\title{
Dampak Game Online terhadap Motivasi Belajar dan Keterampilan Komunikasi Interpersonal Mahasiswa Fakultas Ilmu Komunikasi Universitas Sumatera Selatan
}

\author{
Lovia Evanne ${ }^{1}$, \\ loviaevanne@uss.ac.id \\ Adli $^{2}$ \\ adlimsc@uss.ac.id \\ Ngalimun $^{3}$ \\ alim.pbsid@yahoo.com
}

\begin{abstract}
Communication is a social event that occurs when a human interacts with other humans. The assumptions that there is motivation to learn can be seen with the achievements and cognitive perspectives of students, both elementary school students or college students. The problem of learning motivation in students today is increasingly complex, including online game opium which develops in the dynamics of our society, especiallyIndonesia. This research method is descriptive qualitative. Based on the results of the study it can be concluded (1) There is a positive impact of playing online games on learning motivation. Can be seen from the efforts to increase learning motivation. The cumulative grade point average (GPA) is very satisfying to perfect. (2) There is a positive impact of online games on interpersonal communication skills. Can be seen from the interaction between players in the online game play. Online media-based interpersonal interaction and communication, online games. (3) There is a positive impact of playing online games on learning motivation and interpersonal communication skills. Students who like to play online games have motivation to go to college. This can be seen from the cumulative achievement index (GPA) which is very satisfying to perfect. These students can interact, socialize and communicate well through online game media.
\end{abstract}

Key words: game online, motivation to learn, interpersonal communication 


\section{PENDAHULUAN}

Komunikasi merupakan sebuah peristiwa sosial yang terjadi ketika seorang manusia berinteraksi dengan manusia yang lain. Proses komunikasi bisa terjadi dalam diri seorang individu, dengan orang lain, dan kumpulan-kumpulan manusia dalam proses sosial. Berdasarkan pendapat tersebut, Burgon \& Huffner (2002) membuat klasifikasi tiga jenis komunikasi, yaitu: Komunikasi Intrapersonal, yaitu proses komunikasi yang terjadi di dalam diri individu (internal). Contohnya adalah kegiatan merenung, berpikir, berdialog dengan diri sendiri, baik dalam keadaan sadar maupun tidak. Komunikasi Interpersonal, yaitu proses komunikasi yang terjadi antara satu individu dan individu lain sehingga memerlukan tanggapan (feedback) dari orang lain. Contohnya, perbincangan dengan keluarga, pasangan, teman, rekan kerja, tetangga, dan sebagainya. Komunikasi Massa, yaitu proses komunikasi yang dilakukan kepada sekumpulan manusia di mana di dalamnya terdapat proses sosial, baik melalui media massa atau langsung, dan bersifat satu arah (one way communication). Contohnya adalah kegiatan komunikasi (penyebaran informasi) yang terjadi di hadapan sekumpulan massa, melalui televisi, radio, media internet, media cetak, dan lain-lain. Menurut Suranto (2011 : 79) komunikasi interpersonal yang efektif berfungsi untuk: a) Membentuk dan menjaga hubungan baik antarindividu; b) Menyampaikan pengetahuan/informasi; c) Mengubah sikap dan perilaku; d) Pemecahan masalah hubungan antarmanusia; e) Citra diri lebih baik; f) Jalan menuju sukses. Menurut Suranto, (2011:93) meningkatkan kualitas hubungan interpersonal, maka diperlukan kecakapan komunikasi interpersonal yang baik, sebagai berikut: 1) Komunikasi interpersonal bersifat positif; 2) Ketrampilan Berbicara; 3) Kecakapan Bertanya; 4) Ketrampilan Menjaga Sopan Santun; 5) Cepat, Tanggap, dan Bertanggungjawab; 6) Kecakapan Menyampaikan Informasi; 7) Kecakapan Mendengarkan. Berbagai macam cara untuk meningkatkan kemampuan komunikasi interpersonal mahasiswa yakni: program field study, diskusi kelompok, kegiatan kelompok, organisasi mahasiswa, sosiodrama, psikodrama. Komponen keterampilan berkomunikasi interpersonal yaitu kemampuan mengungkapkan perasaan mahasiswa, kemampuan ini berkaitan dengan penciptaan iklim yang positif dalam kegiatan belajar, yang memungkinkan mahasiswa mau mengungkapkan perasaan dan masalah yang dihadapinya tanpa mereka paksa. Kemampuan menjelaskan perasaan yang diungkapkan mahasiswa. Bila mahasiswa sudah bebas mengungkapkan perasaan/masalah untuk mengklarifikasi ungkapan perasaan tersebut (Ngalimun, 2016:92).

Problematika motivasi belajar pada peserta didik sekarang ini semakin kompleks termasuk candu game online yang berkembang pada dinamika masyarakat kita khususnya Indonesia. Asumsi yang ada motivasi belajar dapat dilihat dengan prestasi dan perspektif kognitif dari peserta didik, baik pelajar sekolah dasar atau mahasiswa perguruan tinggi. Status yang ada tidak banyak menimbulkan perbedaan 
akan motivasi belajar hal ini menjadi sebuah kecenderungan bahwa kesadaran akan motivasi belajar tidak hanya dilihat dari aspek umur dan status tetapi juga dilihat dari gaya hidup masing masing individu. Faktor yang mempengaruhi proses belajar mengajar adalah pertama faktor internal, segala faktor yang bersumber dari dalam diri manusia, contohnya yaitu kemampuan mahasiswa, motivasi, perhatian, persepsi, pemprosesan informasi mencakup (ingatan, lupa,transver). Kedua faktor eksternal, segala faktor yang bersumber dari luar diri mahasiswa, contohnya yaitu kondisi belajar dan pemberian umpan balik (Ngalimun, 2016:92). Jadi dapat disimpulkan bahwa motivasi belajar adalah keseluruhan daya penggerak didalam diri siswa yang menimbulkan kegiatan belajar menjamin kelangsungan dan memberikan arah pada kegiatan belajar sehingga tujuan yang dikehendaki dapat tercapai. Dalam motivasi belajar dorongan merupakan kekuatan mental untuk melakukan kegiatan dalam rangka pemenuhan harapan dan dorongan dalam hal ini adalah pencapaian tujuan.

Game adalah aktivitas yang bersifat reaksi yang mengikut sertakan satu atau lebih pemain. Biasanya game melibatkan kompetensi diantara dua atau lebih pemain. Game bisa dijelaskan sebagai sebuah tujuan yang harus dicapai oleh seorang pemain dan beberapa perangkat pengaturan yang menentukan apa yang harus dilakukan oleh pemain. Seorang filosofi bernama David Kelley (Dwiastuti, 2005:43) dalam bukunya the art of reasoning, mendefinisikan konsep game sebagai sebuah bentuk rekreasi dimana terdapat seperangkat aturan yang menspesifikan objek yang harus di kumpulkan. Definisi game mencangkup hampir keseluruhan game akan tetapi tidak cukup tepat pemain seperti permainan perang dan olahraga, dimana seringkali permainan tidak dilakukan untuk hiburan akan tetapi untuk meningkatkan keterampilan. Game online adalah media elektronik yang menyuguhkan berupa tampilan gerak, warna, suara yang memiliki aturan main dan terdapat level tertentu, yang bersifat menghibur dan bersifat adiktif. Secara operasional game online adalah sebuah permainan yang memiliki konsep permainan yang menarik, memiliki gambar tiga dimensi dan memiliki efekefek yang luar biasa. Game online adalah game yang menggunakan network komputer atau internet. Kecanggihan teknologi yang disajikan dalam permainan jaringan ini, seorang gamer bisa bertemu dengan gamer lain di seluruh dunia yang berada jauh sekalipun. Game dengan fasilitas online via internet menawarkan fasilitas lebih dibandingkan dengan game biasa (video game) karena para pemain itu bisa berkomunikasi dengan pemain lain diseluruh penjuru dunia melalui media chatting. Adiksi terhadap game online adalah kesenangan bermain game karena memberi rasa kepuasan tersendiri, sehingga ada perasaan untuk mengulangi lagi kegiatan yang menyenangkan ketika bermain game online. Ketertarikan pada game online sudah dimulai sejak anak-anak sekitar usia tujuh tahun. Anak mulai merasa senang bermain game, kemudian seiring bertambah usia anak-anak menjadi semakin bersemangat bila akan bermain game. Lama-lama ketertarikan terhadap game online semakin bertambah dan meningkat hingga anak-anak tumbuh menjadi remaja, baik frekuensi maupun durasinya. Menurut Bunny [http://www.pembelajar.com], "kebanyakan game 
dirancang sedemikian rupa agar gamer penesaran dan mengejar nilai tinggi, dan sering membuat gamer lupa bahkan untuk sekedar berhanti sejenak". Remaja yang kecanduan dalam permainan game online termasuk dalam tiga kriteria yang ditetapkan WHO (World Health Organization), yaitu sangat dibutuhkan permainan gejala yang sangat menarik diri dari lingkungan, kehilangan kendali, dan tidak peduli dengan kegiatan lainya (pikiran rakyat, 2008:19). Banyak remaja yang menghabiskan waktu dan uangnya untuk bermain game online. Tidak jarang waktu belajar dan bersosialisasi dengan teman sebaya menjadi berkurang, atau bahkan sama sekali remaja tidak mempunyai waktu untuk belajar dan bersosialisasi. Game online merupakan sebuah gaya hidup baru bagi beberapa orang disetiap kalangan umurnya.

Sekarang ini banyak kita jumpai warung internet (warnet) dikota ataupun di desa-desa dan mereka memfasilitasi akan adanya game online tersebut. Komputer (PC) yang mempunyai spesifikasi untuk game bukanlah komputer yang biasa dan sering kita pakai, harga komputer tersebut lebih mahal dari pada komputer biasa. Terlebih lagi koneksi internet untuk sebuah game online juga harus memadai. Jika kita lihat dari modal untuk sebuah "Game Center" yaitu tempat bermain khusus game online cukup besar, Realita pada masyarakat kita dikota maupun didesa game center sangat mudah kita jumpai dan keberadaannya menjadi candu bagi beberapa orang. Dalam perspektif sosiologi orang yang menjadikan game online sebagai candu, cenderung akan menjadi egosentris dan mengedepankan individualis. Hal ini berbahaya bagi kehidupan sosial individu tersebut, mereka dengan sendirinya menjauh dari lingkungan sekitar dan dimungkinkan akan memarjinalkan diri sehingga beranggapan bahwa kehidupanya adalah di dunia maya dan lingkungannya sosialnya hanya pada dimana tempat dia bermain game tersebut. Banyak diantara mereka dari golongan pelajar sekolah dasar sampai jenjang perguruan tinggi, baik dari status dan golongan ekonomi menengah keatas sampai menengah kebawah. Paradigma dalam sebuah perkembangan teknologi adalah untuk membantu dan menstimulus motivasi belajar baik aspek kognitif maupun psikomotor para peserta didik di era modernisasi sekarang. Tetapi faktanya perkembangan teknologi dan adanya game online membuat arus balik sehingga mayoritas para pecandu game online menurunkan motivasi belajar mereka. Hal ini mungkin saja termasuk peserta didik (mahasiswa) di Fakultas Ilmu Komunikasi Universitas Sumatera Selatan.

\section{TINJAUAN PUSTAKA}

\section{Game Online}

Menurut Webster Dictionary edisi tahun 1913 istilah game didefiniskan sebagai "A contest, physical or mental, according to certain rules, for amusement, recreation, or for winning a stake; as, a game of chance; games of skill; field games, etc."

Pada ensiklopedia Wikipedia definisi game lebih mendalam: "...is a recreational activity involving one or more players, defined by a) a goal that the players try to reach, and $b$ ) 
some set of rules that determines what the players can do. Games are played primarily for entertainment or enjoyment."(http://en.wikipedia.org/wiki/Online_game).

Wikipedia definisi tentang permainan komputer: A computer game is any sort of game that is played using a computer. The term is usually used in reference to games played using a personal computer.(http://en.wikipedia.org/wiki/Online_game).

Game online jika diterjemahkan secara bebas adalah permainan online. Kata permainan memiliki arti sebuah aktivitas rekreasi dengan tujuan bersenang-senang, mengisi waktu luang, atau berolahraga ringan. Permainan biasanya dilakukan sendiri atau bersama-sama. Beberapa permainan ini tercipta di masa yang lalu, disebut dengan permainan tradisional, sedangkan di sisi lain beberapa permainan yang lebih akhir (dan biasanya menggunakan peralatan yang canggih) disebut permainan modern. Permainan online (online game) adalah jenis permainan video atau permainan komputer dengan menggunakanjaringan komputer, umumnya internet, sebagai medianya. Permainan online terdiri dari dua unsur utama, yaitu server dan client. Server adalah penyedia layanan gaming yang merupakan basis agar client-client yang terhubung dapat memainkan permainan dan melakukan komunikasi dengan baik. Suatu server pada prinsipnya hanya melakukan administrasi permainan dan menghubungkan client-client. Sedangkan client adalah pengguna permainan dan memakai kemampuan server.

\section{Motivasi Belajar}

Faktor yang mempengaruhi proses belajar mengajar adalah pertama faktor internal, segala faktor yang bersumber dari dalam diri manusia, contohnya yaitu kemampuan mahasiswa, motivasi, perhatian, persepsi, pemprosesan informasi mencakup (ingatan, lupa, transver). Kedua faktor eksternal, segala faktor yang bersumber dari luar diri mahasiswa, contohnya yaitu kondisi belajar dan pemberian umpan balik (Ngalimun, 2016:92).

Pengertian motivasi menurut para ahli, motivasi berasal dari kata "motif" yang diartikan sebagai daya upaya yang mendorong seseorang untuk melakukan sesuatu.

Menurut Sardiman (2006:73) motif merupakan daya penggerak dari dalam untuk melakukan kegaiatan untuk mencapai tujuan.

Definisi Motivasi adalah perubahan energi dalam diri (pribadi) seseorang yang ditandai dengan timbulnya perasaan dan reaksi untuk mencapai tujuan (Hamalik, 1992:173). Dalam Sardiman (2006:73) motivasi adalah perubahan energi dalam diri seseorang yang ditandai dengan munculnya "felling" dan didahului dengan tanggapan terhadap adanya tujuan.

Menurut Mulyasa (2003:112) motivasi adalah tenaga pendorong atau penarik yang menyebabkan adanya tingkah laku ke arah suatu tujuan tertentu. Peserta didik akan bersungguh-sungguh karena memiliki motivasi yang tinggi. Seorang siswa akan belajar bila ada faktor pendorongnya yang disebut motivasi. 
Jadi dapat disimpulkan bahwa motivasi belajar adalah keseluruhan daya penggerak didalam diri siswa yang menimbulkan kegiatan belajar menjamin kelangsungan dan memberikan arah pada kegiatan belajar sehingga tujuan yang dikehendaki dapat tercapai. Dalam motivasi belajar dorongan merupakan kekuatan mental untuk melakukan kegiatan dalam rangka pemenuhan harapan dan dorongan dalam hal ini adalah pencapaian tujuan.

\section{Komunikasi Interpersonal}

Berdasarkan pendapat tersebut, Burgon \& huffner (2002) Komunikasi interpersonal, yaitu proses komunikasi yang terjadi antara satu individu dan individu lain sehingga memerlukan tanggapan (feedback) dari orang lain. Contohnya antara lain perbincangan dengan keluarga, pasangan, teman, rekan kerja, tetangga dan sebagainya.

Komunikasi interpersonal dalam kegiatan proses belajar mengajar adalah komunikasi yang terjadi antara dosen dengan mahasiswa. Keefektifan komunikasi tersebut tergantung kedua belah pihak, namun karena dosen yang memegang kendali maka tanggung jawab terjadinya komunikasi interpersonal yang sehat dan efektif terletak ditangan dosen (Ngalimun, 2016:92).

Komponen ketrampilan berkomunikasi interpersonal yaitu kemampuan untuk mengungkapkan perasaan mahasiswa, kemampuan ini berkaitan dengan penciptaan iklim yang positif dalam kegiatan belajar, yang memungkinkan mahasiswa mau mengungkapkan perasaan dan masalah yang dihadapinya tanpa mereka paksa. Kemampuan menjelaskan perasaan yang diungkapkan manusia. Bila manusia sudah bebas mengungkapkan perasaan/masalah yang dihadapinya, tugas dosen kini adalah membantu mahasiswa untuk mengklarifikasi ungkapan perasaan tersebut (Ngalimun, 2016:93).

Komunikasi interpersonal sebagai bentuk perilaku, dapat berubah dan sangat tidak efektif. Pada suatu saat komunikasi bisa lebih buruk dan pada saat yang lain bisa lebih baik. Namun demikian, perlu diingat bahwa setiap tindakan komunikasi adalah berbeda dan mempunyai keunikan-keunikan sendiri. Sehingga prinsip-prinsip yang dibicarakan disini harus diterapkan secara fleksibel.

Karakteristik-karakteristik efektivitas komunikasi interpersonal oleh Yoseph Devito Mirhaeni (2008) dilihat daru dua perspektif, yaitu:

a. Humanistis, meliputi sifat-sifa: keterbukaan, perilaku suportif, perilaku positif, empati, kebersamaan.

b. Pragmatis, meliputi sifat-sifat: bersikap yakin, kebersamaan, manajemen interaksi, perilaku ekspresif, orientasi pada orang lain.

\section{METODE PENELITIAN}

Metode penelitian ini adalah deskriptif kualitatif. Adapun teknik yang digunakan untuk mengumpulkan data adalah teknik pengumpulan data kualitatif. 
Teknik yang dipakai dalam penelitian kualitatif yaitu pertama teknik wawancara adalah berupa kontak langsung dengan tatap muka (face to face relationship) antara pencari informasi dengan sumber informasi. Kedua, observasi adalah teknik pengumpulan data yang dipakai untuk menghimpun data penelitian melalui pengamatan dan pengindraan. Ketiga, dokumentasi adalah yang digunakan adalah indikator prestasi berupa kartu hasil studi (KHS).

Populasi dalam penelitian adalah seluruh mahasiswa Fakultas Ilmu Komunikasi Universitas Sumatera Selatan berjumlah 37 orang. Sedangkan sampel adalah jumlah mahasiswa yang hobi bermain game online berjumlah 4 orang. Untuk teknik pemeriksaan keabsahan data, peneliti menggunakan triangulasi teknik dengan melakukan observasi, wawancara mendalam dan dokumentasi. Teknis analis data kualitatif

\section{HASIL PENELITIAN DAN PEMBAHASAN}

Dengan melakukan penelitian ini maka peneliti dapat memperoleh informasi dari mahasiswa yang hobi bermain game online mengenai motivasi belajar dan kemampuan komunikasi interpersonal. Setelah data direduksi, maka didapat data sebagai berikut:

\section{Tabel}

Dokumen Kartu Hasil Studi Informan

\begin{tabular}{|l|l|c|c|}
\hline No. & \multicolumn{1}{|c|}{ Nama } & NIM & $\begin{array}{c}\text { Indeks Prestasi } \\
\text { Komulatif (IPK) }\end{array}$ \\
\hline 1. & Reza Mahendra & 19702010002 & 3,35 \\
\hline 2. & Tri Ortega & 19702010010 & 3,36 \\
\hline 3. & Bayu Pratama Putra & 19702010039 & 4,00 \\
\hline 4. & Reza Aggung Pratama & 19702010040 & 3.55 \\
\hline
\end{tabular}

Berdasarkan hasil temuan dapat disimpulkan sebagai berikut:

1. Didapat data dokumen Reza Mahendra NIM 19702010002 berupa kartu hasil studi (KHS) semester 1 meraih indeks prestasi komulatif (IPK) berjumlah 3,35. Didapat bahwa sejak SD bermain game online, intensitas sehari sekali selama 3 jam. Game online dirasakan tidak ada dampak positif. Ada upaya meningkatkan motivasi belajar. Harapan agar sarana dan prasarana untuk memotivasi belajar sudah lengkap. Dapat disimpulkan bahwa tidak terdapat dampak positif namun adanya upaya meningkatkan motivasi belajar dan dapat dibuktikan dengan indeks prestasi komulatif (IPK) sangat memuaskan.

2. Didapat data dokumen Tri Ortega NIM 19702010010 berupa kartu hasil studi (KHS) semester 1 meraih indeks prestasi komulatif (IPK) berjumlah 3,65. Didapat bahwa bermain game online sejak kelas 6 SD/tahun 2010/2011, intensitas bermain 3-5 jam sehari. Game online ada dampak positif yaitu bisa menghibur dan mendapatkan 
teman yang jauh sekalipun dan membuat diri bersosialisasi kepada orang yang belum dikenal. Ada upaya meningkatkan motivasi belajar. Memotivasi belajar agar bisa sukses dan membuat orang tua bahagia serta tidak menyusahkan orang lain. Dapat disimpulkan bahwa terdapat dampak positif dan adanya upaya meningkatkan motivasi belajar dan dapat dibuktikan dengan indeks prestasi komulatif (IPK) sangat memuaskan.

3. Didapat data dokumen Bayu Pratama Putra NIM 19702010039 berupa kartu hasil studi (KHS) semester 1 meraih indeks prestasi komulatif (IPK) berjumlah 4,00. Didapat bahwa tahun 2018 hingga saat ini bermain game online 2 kali sehari sekitar 5-7 jam sehari. Game online sangat ada dampak positif. Contohnya mengurangi stress, kerjasama tim, menghibur diri dan menghibur orang lain. Motivasi belajar sangat tinggi. Memotivasi belajar agar bisa sukses dan bisa membanggakan kedua orang tua. Dapat disimpulkan bahwa sangat terdampak positif dan motivasi belajar sangat tinggi dan dapat dibuktikan dengan indeks prestasi komulatif (IPK) sempurna.

4. Didapat data dokumen Reza Aggung Pratama NIM 19702010040 berupa kartu hasil studi (KHS) semester 1 meraih indeks prestasi komulatif (IPK) berjumlah 3,55. Didapat bahwa sejak tahun 2018, bermain game online 2-5 jam perhari. Dampak positif dari bermain game online bisa menghilangkan capek dan juga berkomunikasi dengan teman. Tidak ada upaya meningkatkan motivasi belajar. Memotivasi belajar agar perkuliahan tidak dengan media sosial supaya tidak bermalas-malasan. Dapat disimpulkan bahwa terdapat dampak positif dan tidak ada upaya meningkatkan motivasi belajar dan dapat dibuktikan dengan indeks prestasi komulatif (IPK) sangat memuaskan.

\section{KESIMPULAN}

Berdasarkan hasil penelitian tentang Dampak Game Online Terhadap Motivasi Belajar Dan Keterampilan Komunikasi Interpersonal Mahasiswa Fakultas Ilmu Komunikasi Universitas Sumatera Selatan. Oleh karena itu, dapat disimpulkan beberapa hal sebagai berikut:

1. Didapat dampak positif dari bermain game online terhadap motivasi belajar. Dapat dilihat dari adanya upaya meningkatkan motivasi belajar. Nilai indeks prestasi komulatif (IPK) yang sangat memuaskan hingga sempurna.

2. Didapat dampak positif dari game online terhadap kemampuan komunikasi interpersonal. Dapat dilihat dari adanya interaksi antara pemain didalam permainan game online tersebut. Interaksi dan komunikasi interpersonal berbasis media online yaitu game online.

3. Didapat dampak positif dari bermain game online terhadap motivasi belajar dan kemampuan komunikasi interpersonal. Mahasiswa yang hobi bermain game online memiliki motivasi untuk kuliah. Hal tersebut dapat dilihat dari indeks prestasi komulatif (IPK) yang sangat memuaskan hingga sempurna. Mahasiswa tersebut 
dapat berinteraksi, bersosialisasi dan berkomunikasi dengan baik melalui media game online.

\section{DAFTAR PUSTAKA}

Ardianto, Elvinaro. 2010. Metode Penelitian untuk Public Relation. Bandung: Simbiosa Rekatama Media.

Darsono, Max. dkk. 2000. Belajar dan Pembelajaran. Semarang: IKIP Semarang Press.

Dimyati. 2005. Belajar dan Pembelajaran. Jakarta: Depdikbud.

Hamalik, Oemar. 2003. Proses Belajar Mengajar. Bandung: Bumi Aksara.

Izzaty, Rita Eka. 2008. Perkembangan Peserta Didik. Yogyakarta: UNY Press.

Kriyantono, Rachmat. 2020. Tekhnik Praktis Riset Komunikasi. Jakarta: Kencana Prenada Media Group.

Liliweri. 2015. Komunikasi Antar Personal. Jakarta: Kencana Prenada Media Group Ngalimun, Harles. 2017. Ilmu Komunikasi Sebuah Pengantar Praktis, Banjarmasin: Pustaka Banua.

Sardiman, A.M. 2006. Interaksi dan Motivasi Belajar Mengajar. Jakarta: Grafindo. Sugiyono. 2011. Metode Penelitian Kuantitatif, Kualitatif dan RED. Bandung: Alfabeta. Sukardi. 2008. Metode Penelitian Pendidikan: Kompetensi Dan Praktiknya. Jakarta: Bumi Aksara. 